\title{
HIGH AFFINITY BINDING OF SUBSTRATE AND EFFECTOR LIGANDS TO TESTICULAR MICROSOMAL CYTOCHROME P-450*
}

\author{
Patrick G. Quinn $\dagger$ and Anita H. Payne $\ddagger$ \\ Departments of Biological Chemistry and Obstetrics and Gynecology and The Reproductive \\ Endocrinology Program, The University of Michigan, Ann Arbor, MI 48109-0278, U.S.A.
}

(Received 28 March 1986)

\begin{abstract}
Summary-The binding characteristics of substrate and effector ligands to testicular microsomal cytochrome $\mathrm{P}-450$ (17 $\alpha$-hydroxylase/ $\mathrm{C}_{17-20}$ lyase) have been investigated by difference spectroscopy. Steroid products and their analogs induce oxygen-mediated damage of microsomal P-450 activities of cultured Leydig cells, whereas testosterone acetate protects P-450 from this damage [1]. Progesterone and $17 \alpha$-hydroxyprogesterone, the enzyme's substrates, bound stoichiometrically to microsomal P-450 with unusually high affinity $\left(K_{d}=23-51 \mathrm{nM}\right)$. These properties of the enzyme may be responsible for the extremely efficient metabolism of these intermediates in androgen biosynthesis. The binding affinities of inhibitory effector ligands were determined in competition experiments with the substrates. Several steroids which have varying effects on damage of P-450 in cultured Leydig cells inhibited substrate binding similarly $\left(K_{\mathrm{dl}}=3.8-12.8 \mu \mathrm{M}\right)$. Aminoglutethimide did not inhibit substrate binding. The results suggest that steroid binding to P-450 is necessary but not sufficient to increase oxygen free-radical damage of the testicular microsomal P-450. Testosterone acetate, which diminishes P-450 loss in Leydig cell cultures, was also bound stoichiometrically with high affinity $\left(K_{\mathrm{d}}=17 \mathrm{nM}\right)$ and produced a unique spectra, with maxima at $408 \mathrm{~nm}$, an isosbestic point at $418 \mathrm{~nm}$ and minima at $428 \mathrm{~nm}$. Therefore, the protection of P-450 in cultured Leydig cells probably results from binding of testosterone acetate at the active site of P-450.
\end{abstract}

\section{INTRODUCTION}

The hydroxylation of progesterone to form $17 \alpha$-hydroxyprogesterone and the subsequent cleavage of the two carbon side-chain of the latter steroid to form androstenedione are catalyzed by a cytochrome P-450 enzyme of the smooth endoplasmic reticulum in mammalian testes $[2,3]$. Recently, an apparently homogeneous P-450 enzyme, which catalyzed both the hydroxylase and lyase reactions, has been purified from pig testes microsomes [4]. The regulation of these P-450 activities by luteinizing hormone (LH) has been studied in detail. Both enzyme activities, as well as the P-450 content of microsomes, are increased by chronic treatment of intact or hypophysectomized rats with $\mathrm{LH}$ or its analog, human chorionic gonadotropin (hCG) $[5,6]$. In contrast, acute treatment of rats or of purified Leydig cells maintained in culture with high doses of LH or hCG causes a decrease in hydroxylase and lyase activities as well as a decrease in P-450 content [6-11]. Studies of purified cultured Leydig

*This work was supported by National Institutes of Health Grant HD-08358.

†Present address: Department of Molecular Physiology and Biophysics, School of Medicine, Vanderbilt University, Nashville, TN 37232, U.S.A.

†Address for correspondence: Steroid Research Unit, L1221-0278 Women's Hospital, 1500 E. Medical Center Dr., University of Michigan, Ann Arbor, MI 48109-0278, U.S.A. cells have demonstrated that both the positive (chronic) and negative (acute) effects of $\mathrm{LH} / \mathrm{hCG}$ are mediated by cyclic AMP $[10,12]$.

The acute cAMP-stimulated loss of P-450 activities in Leydig cells is due to oxygen-mediated damage of the cytochrome, induced by interaction of steroid products with the P-450[1,10]. The cAMPstimulated decrease in P-450 activities could be prevented by reduction of the oxygen tension in which Leydig cells were cultured or by blocking the cAMPstimulated increase in steroid production with aminoglutethimide. The oxygen-tension sensitive decrease in P-450 activities could be induced by treatment of Leydig cells with steroid products or product analogs, as well as with cAMP. Therefore, we proposed that the decrease in microsomal P-450 activities of Leydig cells resulted from oxygen free-radical damage of the cytochrome P-450, initiated by binding of the steroid product to form a pseudosubstrate- $\mathrm{P}-450-\mathrm{O}_{2}$ complex. This type of complex releases damaging oxygen free-radicals because the pseudosubstrate cannot be hydroxylated. In contrast to several other steroids, testosterone acetate actually preserved rather than destroyed the P-450 activities of cultured Leydig cells.

The current study investigates the characteristics of binding of substrates and other effector steroids to microsomal P-450 preparations obtained from mouse testes. The binding of the substrates, progesterone and 17a-hydroxyprogesterone, and the protective ligand, testosterone acetate, all of which produce a strong spectral signal, were monitored directly by 
difference spectroscopy. The binding of other effector ligands, steroids that affect the P.450 activities of cultured Leydig cells, was evaluated in competition experiments with the substrate ligands.

\section{EXPERIMENTAL}

\section{Preparation of microsomes}

Adult male outbred mice were killed by cervical dislocation and the testes were collected on ice. Decapsulated testes were homogenized in $3 \mathrm{vol}$ of ice-cold phosphate-EDTA buffer $\left(100 \mathrm{mM} \mathrm{KPO}_{4}\right.$, $1 \mathrm{mM}$ EDTA, pH 7.4) containing $25 \mathrm{mM}$ sucrose with 7 strokes of a Teflon-glass homogenizer (Potter-Elvehjem). The resulting homogenate was centrifuged at $15,000 \mathrm{~g}$ for $30 \mathrm{~min}$ to remove mitochondria, nuclei and cell debris. The supernatant was then centrifuged at $100,000 \mathrm{~g}$ for $60 \mathrm{~min}$ and the microsomal pellet was collected. The microsomes were washed by resuspending the pellet in phosphate-EDTA buffer and resedimenting the pellet at $100,000 \mathrm{~g}$ for $60 \mathrm{~min}$. The washed microsomal pellet was resuspended (microsomes from 4 testes per ml) in phosphate-EDTA buffer containing $20 \%$ glycerol and stored at $-70^{\circ} \mathrm{C}$ until use.

\section{Spectrophotometric assays}

All spectrophotometric data were obtained as difference spectra at room temperature on an Aminco DW2 dual beam spectrophotometer, scanning from 350 to $550 \mathrm{~nm}$ with a $3.0 \mathrm{~mm}$ slit width. The concentration of cytochrome $\mathrm{P}-450$ was determined from the difference $\left(\mathrm{A}_{450}-\mathrm{A}_{490}\right)$ of the CO-saturated reduced complex minus the reduced complex, using an absorption coefficient of $91 \mathrm{mM}^{-1} \mathrm{~cm}^{-1}$, as described by Omura and Sato [13]. Steroids were obtained from Sigma and Steraloids and were recrystallized prior to use. Steroids were dissolved in methanol so that the appropriate concentration could be added in small aliquots and the final $\mathrm{MeOH}$ concentration would not exceed $5 \%(\mathrm{v} / \mathrm{v})$.

The binding of ligands producing a strong spectral signal was determined from difference spectra at the appropriate wavelengths; $A_{300}-A_{420}$ for progesterone and $17 \alpha$-hydroxyprogesterone and $A_{408}-A_{428}$ for testosterone acetate. The steroid was added in a small volume of $\mathrm{MeOH}$ to the sample cuvette and an equivalent volume of $\mathrm{MeOH}$ was added to the reference cuvette and the contents of both were mixed with a glass rod. Equilibration was rapid; spectra recorded $15-30 \mathrm{~min}$ after addition of steroids were identical to those recorded 2-3 min after steroid addition. Since binding of these ligands was stoichiometric at total ligand $\left[L_{1}\right]$ concentrations less than the concentration of P-450 $\left[\mathrm{P}_{1}\right], \Delta$ absorption coefficients $(\Delta \epsilon)$ were determined and used to calculate the concentration of $\mathrm{P}-450$-ligand complex: $[\mathrm{PL}]=$ $\Delta \mathbf{A} / \Delta \epsilon 1$. Dissociation constants for these ligands were determined by mixing equimolar amounts of P-450 and ligand and recording the spectral signal
$(\Delta \mathrm{A})$, followed by serial 2 -fold dilution of the samples, which favors dissociation of the PL complex. The concentration of P-450-ligand complex [PL] was calculated as described above and the concentration of free ligand [L] was calculated by subtraction from total ligand $\left([\mathrm{L}]=\left[\mathrm{L}_{\mathrm{t}}\right]-[\mathrm{PL}]\right)$. The data from at least 3 dilutions were used to calculate the fraction bound $\left(r=[\mathrm{PL}] /\left[\mathrm{P}_{\mathrm{t}}\right]\right)$ and the dissociation constants for these ligands $\left(\mathrm{K}_{\mathrm{dL}}\right)$ were obtained from the slopes of Scatchard plots (r/L] vs r). These experiments were repeated with at least two different preparations of microsomal P-450 for each ligand.

The dissociation constants for inhibitory ligands (I) were determined from competition experiments with the chromogenic ligands (L), progesterone and $17 \alpha$-hydroxyprogesterone. For these experiments, the difference in absorbance $\left(\mathrm{A}_{390}-\mathrm{A}_{450}\right)$ for an equimolar concentration of P-450 and ligand (L) was determined in the absence of $I$ and in the presence of $20-320 \mu \mathrm{M} \mathrm{I}$, which was added to both the sample and reference cuvettes in a small volume of $\mathrm{MeOH}$. The data were analyzed according to the method of Bessler et al.[14], describing the competition of a chromogenic ligand (L) and an inhibitory ligand (I) for a protein $(\mathrm{P}),(\mathrm{P}+\mathrm{L}+\mathrm{I} \rightleftharpoons \mathrm{PL}+\mathrm{PI})$. The concentrations of $\mathrm{PL}([\mathrm{PL}]=\Delta \mathrm{A} / \Delta \epsilon])$ and $\mathrm{L} \quad([\mathrm{L}]=$ $\left.\left[\mathbf{L}_{\mathrm{l}}\right]-[\mathrm{PL}]\right)$ were determined for each concentration of inhibitor (I) and plotted as $\left(\left[\mathrm{P}_{\mathrm{t}}\right] /[\mathrm{PL}]\right)-1[\mathrm{~L}] \mathrm{vs}[\mathrm{I}]$ (assuming $K_{\mathrm{dL}}=0$, where $K_{\mathrm{du}}$ is the dissociation constant for the ternary complex PLI). The slope of this plot gives the ratio of dissociation constants for $\mathrm{L}$ and $\mathrm{I}\left(\mathrm{m}=K_{\mathrm{dL}} / K_{\mathrm{dl}}\right)$, as in equation 4 of Bessler $e t$ al. [14], $\left(\left[\mathrm{P}_{\mathrm{t}}\right] /[\mathrm{PL}]-1\right)[\mathrm{L}]=\left(K_{\mathrm{dL}}[\mathrm{I}]\right) / K_{\mathrm{di}}$. The slopes of these lines were determined by linear regression and $K_{\mathrm{dI}}$ was determined from these slopes and the values for $K_{\mathrm{dL}}$ determined in the dilution experiments described above.

\section{RESULTS}

\section{Binding affinities of chromogenic ligands}

The binding of progesterone, $17 \alpha$-hydroxyprogesterone or testosterone acetate to microsomal P.450 of mouse testis is accompanied by pronounced spectral changes. The change in $\Delta$ absorbance obtained from difference spectra as a function of total ligand concentration $\left[\mathrm{L}_{t}\right]$, is illustrated in Fig. 1 . The change in $\Delta$ absorbance was large and directly proportional to the concentration of ligand added for ligand concentrations ranging from 0 to $75 \%$ of the P-450 concentration. There was also a small increase in $\Delta$ absorbance at high ligand concentrations. The insets to Fig. 1 illustrate the linear relationship of $\Delta A$ to $\left[L_{t}\right]$, which indicates stoichiometric binding of the ligand to the microsomal P-450. Since all the ligand is bound to $\mathrm{P}-450$ over this range, the $\Delta$ absorption coefficient $(\Delta \epsilon)$ for the P-450-ligand complex ([PL]) can be accurately determined and used to calculate $[\mathrm{PL}]$ under conditions where the concentration of free 


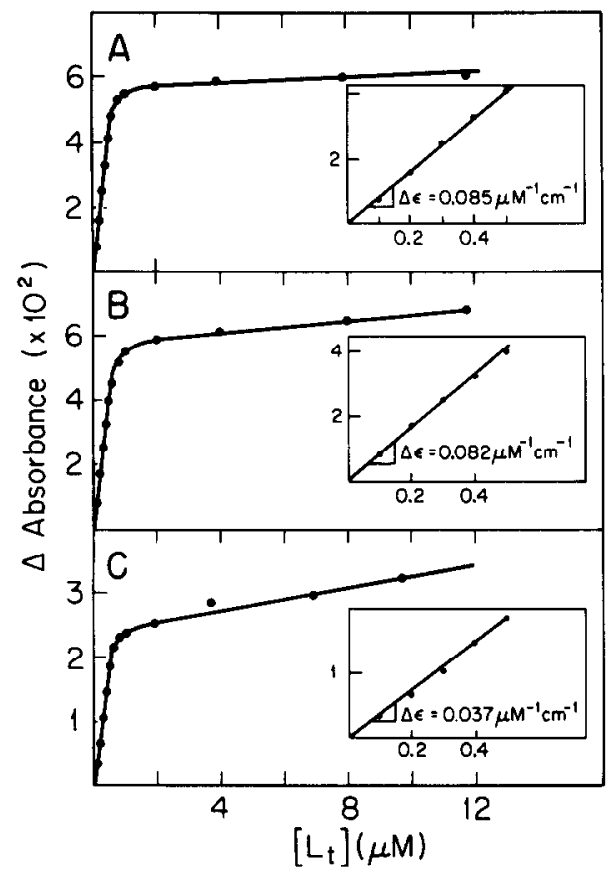

Fig. 1. Titration of testicular microsomal P-450 with chromogenic ligands. The indicated concentration of steroid ligand $\left(L_{t}\right)$ was added to microsomal P-450 $(0.7-0.8 \mu \mathrm{M})$ and the changes in $\Delta$ absorbance of the difference spectra were determined. The chromogenic ligands were: (A) progesterone, (B) $17 \alpha$-hydroxyprogesterone and (C) testosterone acetate. The $\Delta$ absorption coefficient $(\Delta \epsilon)$ for the P-450-ligand complex was determined from the linear portion of the binding curves (expanded in insets), as described in Experimental.

ligand varies in the presence of an inhibitory ligand (below). The small increase in $\Delta \mathrm{A}$ at very high ligand concentrations suggests that these ligands bind nonspecifically to a second class of low affinity sites in these microsomal preparations of testicular P-450. The fact that all three ligands are bound stoichiometrically suggests that all three bind to the same site. Pregnenolone also showed a pattern of binding similar to that illustrated for the other ligands (data not shown).

The stoichiometric binding of these ligands precludes determination of the dissociation constants $\left(K_{\mathrm{dL}}\right)$ by graphical methods relying on the determination of free ligand [L] over a wide range of total ligand concentrations, since $[\mathrm{L}]$ is zero or very small at all ligand concentrations below [P]. Therefore, $K_{\mathrm{dL}}$ was determined by mixing equimolar concentrations of $\mathrm{P}-450$ and ligand (at which point $[\mathrm{L}]$ and $[\mathrm{P}]$ are greatest relative to $[\mathrm{PL}]$ ) and measuring $\triangle \mathrm{A}$ as these samples were serially diluted to promote dissociation of the PL complex. This allows the measurement of $[P L]$ at varying concentrations of $[L]$ for the determination of $K_{\mathrm{dL}}$. This also demonstrates that $K_{\mathrm{dL}}$ is independent of the concentration of P-450. The dissociation constants for the three chromogenic ligands are given in Table 1. All three ligands were bound with unusually high affinity.

\section{Spectral characteristics}

The unique spectral changes produced by binding of testosterone acetate (Fig. 2) to testicular microsomal P-450 have not been reported previously. The binding of progesterone and 17 $\alpha$-hydroxyprogesterone, the substrate for the hydroxylase and lyase reactions, respectively, produced a typical type I spectral shift, as shown in Fig. 3 for $17 \alpha$-hydroxyprogesterone, characterized by a maximum at $390 \mathrm{~nm}$, an isosbestic point at $406 \mathrm{~nm}$ and a minimum at $424 \mathrm{~nm}$, which indicates a shift from the low spin to the high spin form of the cytochrome P-450 [15]. Testosterone acetate is not a substrate for the enzyme [16], but has been shown to have a protective effect on the microsomal P-450 activities of Leydig cells maintained in primary culture [1]. The binding of testosterone acetate by testicular microsomal P-450 was stoichiometric and of high affinity like the binding of the substrates, but differed considerably in its spectral characteristics. As illustrated in Fig. 2, the binding of testosterone acetate produced a unique spectra with maxima at $408 \mathrm{~nm}$, an isosbestic point at $418 \mathrm{~nm}$ and minima at $428 \mathrm{~nm}$. To the best of our knowledge, this is the first report of such a unique spectral shift induced by steroid binding to a P-450.

\section{Inhibition of substrate binding by non-chromogenic steroids}

Competition experiments were done to determine the binding affinities of other steroids that affect the microsomal P-450 activities of Leydig cells but produce little or no spectral change upon addition to microsomal P-450. The binding of these ligands can be measured by determining the decrease in $\mathrm{A}$ re-

Table 1. Dissociation constants for chromogenic ligand binding to testicular microsomal P-450

\begin{tabular}{lcccc}
\hline Ligand (L) & \multicolumn{3}{c}{$\boldsymbol{K}_{\mathrm{dL}}(\mathrm{nM})$} \\
Expt 1 & Expt 2 & Expt 3 & Mean \pm Range \\
\hline Progesterone & 22 & 20 & 26 & $23 \pm 3$ \\
$7 \alpha$-Hydroxyprogesterone & 52 & 50 & N.D. & $51 \pm 1$ \\
Testosterone acetate & 5 & 30 & N.D. & $17 \pm 12$ \\
\hline
\end{tabular}

Equimolar concentrations $(0.75-1.0 \mu \mathrm{M})$ of microsomal P-450 and steroid ligand were mixed and the difference spectrum recorded as the mixture was diluted serially 2-fold, to favor dissociation. The concentrations of bound and free P-450 and ligand were obtained and used to calculate the dissociation constants, $K_{\mathrm{dL}}$, as described in Experimental.

N.D.: not determined. 


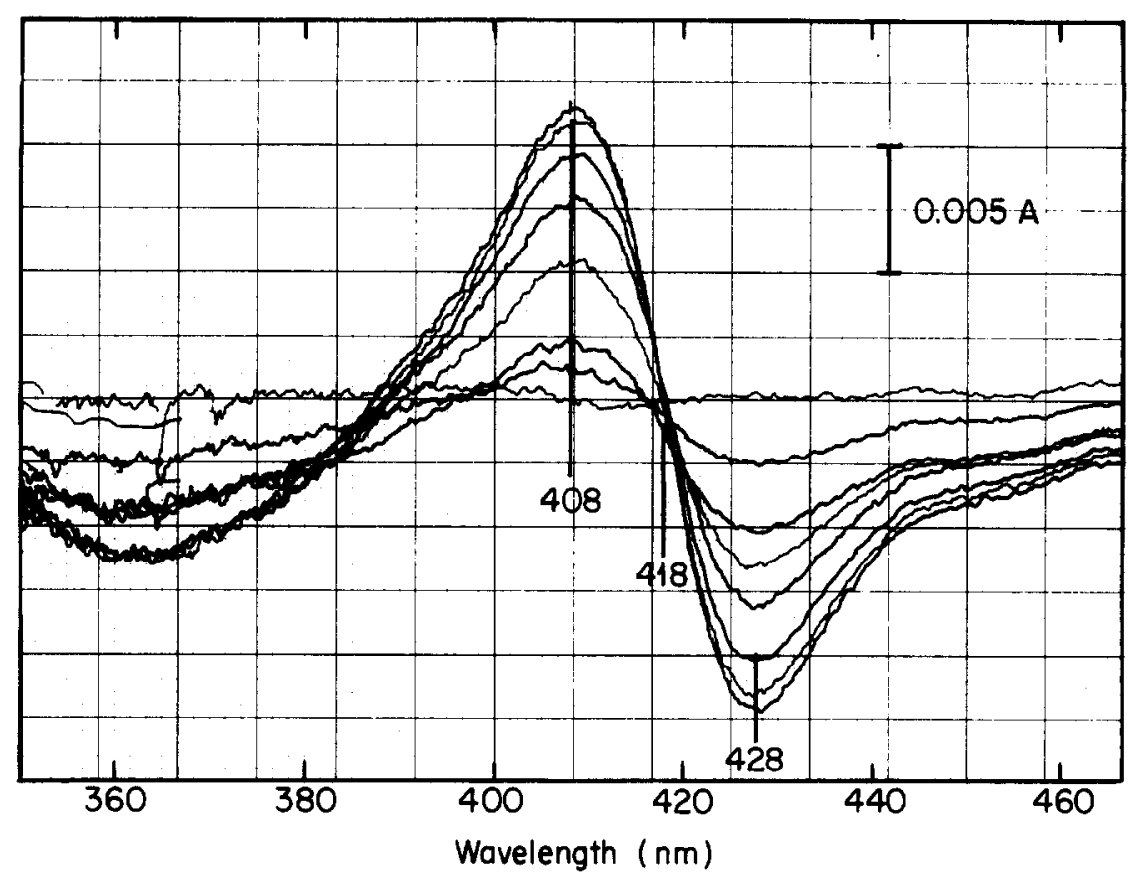

Fig. 2. Difference spectra produced by binding of testosterone acetate to testicular microsomal P-450. Testosterone acetate $(0.1-0.7 \mu \mathrm{M})$ was added to microsomal $\mathrm{P}-450$ in $0.1 \mu \mathrm{M}$ aliquots and difference spectra (increasingly larger) were recorded. The wavelengths of maximum and minimum absorption and of the isosbestic point are indicated.

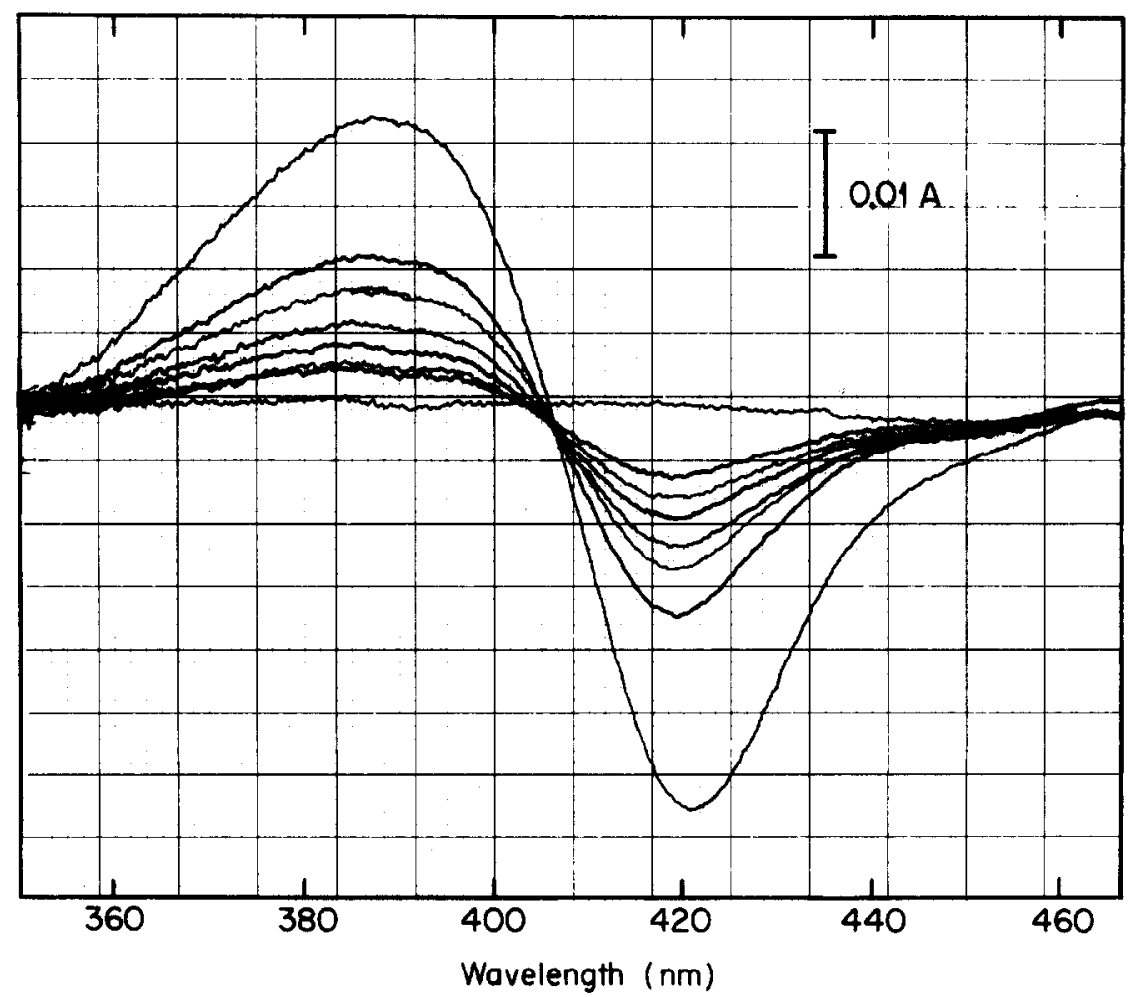

Fig. 3. Inhibition by testosterone of $17 \alpha$-hydroxyprogesterone binding to testicular microsomal P-450. Equimolar concentrations $(0.8 \mu \mathrm{M})$ of microsomal P-450 and $17 \alpha$-hydroxyprogesterone were mixed and increasing concentrations of testosterone were added. Progressively smaller spectra were recorded following the addition of increasing concentrations of testosterone: $0,39,78,117,231$ and $305 \mu \mathrm{M}$, respectively. 


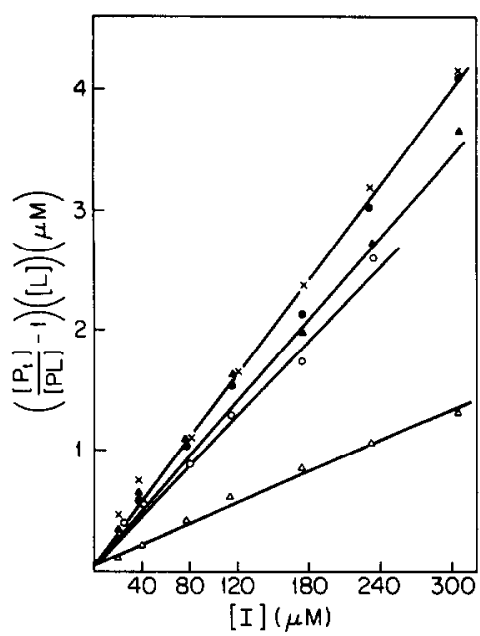

Fig. 4. Determination of dissociation constants for inhibitory ligands. The data from competition experiments were plotted according to equation 4 of Bessler et al. (1974), assuming $K_{\mathrm{dLI}}=0$, as described in Experimental. The slope of the plot is equal to the ratio of the dissociation constants for the chromogenic ligand and the inhibitory ligand ( $m=K_{\mathrm{dL}} / K_{\mathrm{dI}}$ ). In the experiment illustrated, the chromogenic ligand (L) was $17 \alpha$-hydroxyprogesterone and the inhibitory ligands (I) were: $(O)$, testosterone; $(x)$, androstenedione; (A), epitestosterone; $(O)$, estradiol; and $(\triangle)$, cortisol.

sulting from the addition of inhibitory ligands to a preparation of microsomal P-450 which is in equilibrium with bound chromogenic ligand, such as progesterone or $17 \alpha$-hydroxyprogesterone. An example of the changes in difference spectra resulting from the addition of testosterone to an equimolar mixture of testicular microsomal P-450 and $17 \alpha$-hydroxyprogesterone is illustrated in Fig. 3. The largest signal for the difference spectra was obtained in the absence of testosterone and respectively smaller signals were produced by addition of $20-320 \mu \mathrm{M}$ testosterone. It is clear from these spectra that only the magnitude of the signal is changed, and not its characteristics. These experiments were done with an equimolar concentration of P-450 and chromogenic ligand so that most of the high affinity sites but not the low affinity sites would be occupied, rather than with excess ligand. In the presence of a vast excess of chromogenic ligand the affinity of the inhibitory ligand appears to be greater because of displacement of the low affinity binding. The data obtained from these experiments were analyzed with the method of Bessler et al.[14] by plotting the product $\left(\left[\mathrm{P}_{\mathrm{t}}\right] /[\mathrm{PL}]-1\right)[\mathrm{L}]$ against the concentration of the inhibitory ligand [I]. This should yield a straight line if the termolecular complex PLI does not form ( $K_{\mathrm{dLI}}=0$; i.e. both ligands compete for the same site on the protein). As shown in Fig. 4, all steroid ligands which displace $17 \alpha$-hydroxyprogesterone gave linear relationships between $\left(\left[\mathbf{P}_{\mathbf{t}}\right] /[\mathrm{PL}]-1\right)[\mathbf{L}]$ and $[\mathbf{I}]$. Similar data were obtained in a second experiment using $17 \alpha$-hydroxyprogesterone as the chromogenic ligand and in a third experiment using progesterone as the chromogenic ligand. As would be expected, the slopes of the secondary plots from the latter experiment were about one half the magnitude because of the higher affinity of the P-450 for progesterone (Table 2). The average values for $K_{\mathrm{dl}}$ from these experiments are given in Table 2. Cortisol was clearly a less potent inhibitor of substrate binding than were testosterone, androstenedione, epitestosterone and estradiol, which were similar. Aminoglutethimide, a potent inhibitor of the mitochondrial P-450 side-chain cleavage enzyme, did not inhibit binding of substrate to microsomal P-450 when added at concentrations up to $320 \mu \mathrm{M}$.

\section{DISCUSSION}

The data presented herein demonstrate that the substrate ligands, progesterone and $17 \alpha$-hydroxyprogesterone, are bound stoichiometrically and with very high affinity by mouse testicular microsomal cytochrome $P-450$ preparations. Testosterone acetate binding was very similar to substrate binding, except that the characteristics of the difference spectra were distinct from those produced by substrates. The binding of all three ligands showed evidence of a small amount of nonspecific binding in these P-450 preparations. It was also demonstrated that steroid products of the enzyme and other steroids inhibit the binding of substrates in a competitive fashion, but bind far less tightly than the substrates.

Our data concerning the binding of substrates to testicular microsomal P-450 differ in two significant respects from previously reported data. First, the stoichiometric binding of substrate to this P-450 has not been reported previously. Second, the dissociation constants for substrate binding in these microsomal preparations are two orders of magnitude lower than those reported for the purified

Table 2. Dissociation constants for ligands that inhibit substrate binding to testicular microsomal P-450

\begin{tabular}{lcccc}
\hline Inhibitor (I) & Expt 1 & $\begin{array}{c}K_{\mathrm{dI}}(\mu \mathrm{M}) \\
\text { Expt 2 }\end{array}$ & Expt 3 & Mean \pm Range \\
\hline Testosterone & 3.4 & 3.9 & 4.2 & $3.8 \pm 0.4$ \\
Androstenedione & 4.3 & 3.9 & 5.2 & $4.5 \pm 0.7$ \\
Epitestosterone & 4.6 & 4.5 & 5.2 & $4.8 \pm 0.4$ \\
Estradiol & 5.3 & 5.0 & 5.1 & $5.1 \pm 0.2$ \\
Cortisol & 13.6 & 11.9 & N.D. & $12.8 \pm 0.9$ \\
\hline
\end{tabular}

Dissociation constants for inhibitory ligands were determined from competition experiments, as described in Experimental.

N.D.: not determined. 
microsomal P-450 (hydroxylase/lyase) obtained from porcine testes $[4,17,18]$. The higher affinity of microsomal preparations of $\mathrm{P}-450$ for steroid substrates is most likely due to hydrophobic interactions of both the P-450 and steroid substrate with the microsomal membrane. It should be noted that the values determined for the $K_{\mathrm{m}}$ of the hydroxylase and lyase reactions are also lower for microsomal preparations of P-450 [6] than the values determined using the purified enzyme preparation [16-18]. Both the stoichiometric nature of substrate binding and the high affinity of the P-450 for its substrates may be of importance to the control of testicular steroidogenesis. The steady-state concentrations of progesterone and $17 \alpha$-hydroxyprogesterone are very low relative to the concentrations of the products (less than $10 \%$ ), even in Leydig cells which are synthesizing androgens at a maximal rate $^{*}[7,9]$. In addition, we have previously demonstrated that the $\mathrm{P}-450$ activities are present in excess of those required to maintain a maximal rate of steroidogenesis $[1,10]$. Therefore, an excess of P-450 enzyme, which is capable of binding stoichiometric quantities of substrate, would ensure that free intermediate is bound and metabolized to androgens.

The present findings are consistent with the finding that both hydroxylase and lyase activities are associated with a single cytochrome P-450 in testicular microsomes $[4,17]$. The microsomal $P-450$ preparations we used could be titrated completely with either progesterone or $17 \alpha$-hydroxyprogesterone. In addition, the P-450-substrate complexes for both progesterone and $17 \alpha$-hydroxyprogesterone had nearly identical molar absorptivities. Therefore, it would appear that both substrates bind to a single active site on the enzyme, as would be expected.

Neither the stoichiometric, high affinity binding of testosterone acetate to testicular microsomal P-450 nor the unique spectral changes induced by this binding have been reported previously. The demonstration that the P-450 preparation could be titrated fully with testosterone acetate indicates that this steroid also binds to the single active site of the enzyme. Suhara et al.[16] demonstrated that the highly purified testicular hydroxylase/lyase P-450 also catalyzes an oxidase reaction $(17 \beta$-hydroxysteroid $\rightarrow 17$-ketosteroid), but testosterone acetate did not serve as a substrate for this reaction. The stoichiometric, high affinity binding of testosterone acetate is of particular importance in regard to our previous finding that this steroid is capable of preserving microsomal P-450 activities in Leydig cell cultures [1]. In addition, the unique spectral changes induced by testosterone acetate binding to P-450 also support a unique role for testosterone acetate.

The present study demonstrates that products of

*Quinn P. G., Stalvey J. R. D. and Payne A. H.: unpublished observations. the enzyme and other steroids compete with substrate for binding to the P-450 with a similar degree of effectiveness. However, aminoglutethimide, which is a potent inhibitor of mitochondrial P-450 cholesterol side-chain cleavage, was found not to inhibit the binding of substrates to the microsomal P-450 enzyme. The $K_{\mathrm{d}}$ value for estradiol is in agreement with the value determined for the purified enzyme [18]. The apparent $K_{\mathrm{d}}$ 's for inhibitory steroid binding are sufficiently low to be consistent with the hypothesis that binding to the active site is necessary but not sufficient for a steroid to influence the production of oxygen free-radicals by the P-450 complex. It has also been demonstrated that there is no correlation between $\mathrm{H}_{2} \mathrm{O}_{2}$ production or substrate monooxygenation with the optical binding spectra in liver microsomes $[19,20]$. Our results are consistent with these reports.

In summary, our findings demonstrate that testicular microsomal P-450 binds its hydroxylase/lyase substrates stoichiometrically and with very high affinity. These properties of the $\mathrm{P}-450$ are probably responsible, in large part, for the extremely complete and efficient metabolism of progesterone to androgens in Leydig cells. The products of the hydroxylase/lyase as well as epitestosterone, all of which induce oxygen-mediated damage of the P-450, inhibit substrate binding. Testosterone acetate was stoichiometrically bound with high affinity, as are substrates, but produces a unique spectral signal when bound. These results suggest that it protects the P-450 of cultured Leydig cells by binding to the active site of the enzyme.

Acknowledgements-We wish to thank Dr J. A. Shafer for his suggestion of the dilution experiments used to determine $K_{\mathrm{d}}$ values for chromogenic ligands and for many helpful discussions of the data. We also wish to thank Drs L. D. Gorsky and D. R. Koop for their helpful discussions during the course of this study.

\section{REFERENCES}

1. Quinn P. G. and Payne A. H.: Steroid product-induced, oxygen-mediated damage of microsomal cytochrome P-450 enzymes in Leydig cell cultures. J. biol. Chem. 260 (1985) 2092-2099.

2. McMurty R. J. and Hagerman D. D.: Carbon monoxide inhibition of progesterone hydroxylation and side chain cleavage catalyzed by rat testis microsomes. Steroid Lipid Res. 3 (1972) 8-13.

3. Betz G., Tsai P. and Weakley R.: Heterogeneity of cytochrome P-450 in the rat testis microsomes. J. biol. Chem. 251 (1976) 2839-2841.

4. Nakajin S. and Hall P. F.: Microsomal cytochrome P-450 from neonatal pig testis. J. biol. Chem. 256 (1981) 3871-3876.

5. Purvis J. L., Canick J. A., Latif S. A., Rosenbaum J. H., Hologgitas J. and Menard R. H.: Lifetime of microsomal cytochrome P-450 and steroidogenic enzymes in rat testis as influenced by human chorionic gonadotropin. Archs Biochem. Biophys. 159 (1973) 39-49.

6. O'Shaughnessy P. J. and Payne A. H.: Differential effects of single and repeated administration of gonadotropins on testosterone production and steroidogenic 
enzymes in Leydig cell populations. J. biol. Chem. 257 (1982) 11503-11509.

7. Cigorraga S. B., Dufau M. L. and Catt K. J.: Regulation of luteinizing hormone receptors and steroidogenesis in gonadotropin-desensitized Leydig cells. $J$. biol. Chem. 253 (1978) 4297-4304.

8. Chaslow F,, Marr H., Haour F, and Saez J. M.: Testicular steroidogenesis after human chorionic gonadotropin desensitization in rats. J. biol. Chem. 254 (1979) 5613-5617.

9. Nozu K., Dehejia A., Zawistowich L., Catt K. J. and Dufau M. L.: Gonadotropin-induced receptor regu* lation and steroidogenic lesions in cultured Leydig cells. Induction of specific protein synthesis by chorionic gonadotropin and estradiol. J. biol. Chem. 256 (1981) 12875-12882.

10. Quinn P. G. and Payne A. H.: Oxygen-mediated damage of microsomal cytochrome P-450 enzymes in cultured Leydig cells. J. biol. Chem. 259 (1984) 4130-4135.

11. Luketich J. D., Melner M. H., Guengerich F. P. and Puett D.: Effects of human choriogonotropin on mito chondrial and microsomal cytochrome P.450 levels in mouse testes. Biochem. biophys. Res. Commun. 111 (1983) 424429.

12. Malaska T. and Payne A. $H_{n}$ : Luteinizing hormone and cyclic AMP-mediated induction of microsmal cytochrome P-450 enzymes in cultured mouse Leydig cells. J. biol. Chem. 259 (1984) 11654-11657.
13. Omura $T$, and Sato $R$.: The carbon monoxide-binding pigment of liver microsomes. J. biol. Chem. 239 (1964) 2379-2385.

14. Bessler W., Shafer J. A. and Goldstein I. J.: A spectrophotometric study of the carbohydrate binding site of concanavalin A.J. biol. Chem. 249 (1974) 2819-2822.

15. Hildebrandt A., Remmer $H$. and Estabrook R. W.: Cytochrome P-450 of liver microsomes-one pigment or many. Biochem. biophys. Res. Commun. 30 (1968) 607-612.

16. Suhara K., Fujimura Y., Shiroo M. and Katagiri M.: Multiple catalytic properties of the purified and reconstituted cytochrome P-450 (P-450 sccll ) system of pig testis microsomes. J. biol. Chem. 259 (1984) 8729-8736.

17. Nakajin S., Hall P. F. and Onoda M.: Testicular microsomal cytochrome $P-450$ for $C_{21}$ steroid side chain cleavage. J. biol. Chem. 256 (1981) 6134-6139.

18. Onoda $M$. and Hall $P$. $F_{\text {: }}$ Inhibition of testicular microsomal cytochrome P-450 (17 $\alpha$-hydroxylase/ C-17,20-lyase) by estrogens. Endocrinology 109 (1981) 763-767.

19. Ullrich V. and Kuthan $H_{\text {.: }}$ Biochemistry, Biophysics and Regulation of Cytochrome P-450 (Edited by J. A. Gustafsson). Elsevier, North Holland (1980) pp. 267-272.

20. Kuthan H. and Ullrich V.: Oxidase and oxygenase function of the microsomal cytochrome P-450. Eur. J. Biochem. 126 (1982) 583-588. 